\title{
IMPLICAÇÕES DOS CONCEITOS DA SUSTENTABILIDADE NO DESIGN: UMA REVISÃO CRÍTICA
}

Implications of sustainability concepts on design: a critical review

\author{
Jucelia S. Giacomini da Silva \\ Aguinaldo dos Santos
}

\begin{abstract}
Resumo
O design no último século se constituiu em um ativo promotor dos modos de vida atualmente considerados insustentáveis. Desta forma, este estudo tem como objetivo revisar a heurística existente no desenvolvimento sustentável e suas implicações nas atividades do design. Esta revisão crítica do estado da arte enfoca as novas competências exigidas pela profissão do Design e suas implicações na educação para o Design. Os entraves para a disseminação destas novas competências no Brasil incluem a escassez de profissionais especializados, de material didático e de metodologias que habilitem o design para atuar no nível do sistema, incluindo o design de sistemas de produto-serviço.
\end{abstract}

Palavras-chave: Design de Sistemas para a Sustentabilidade; Sistema produto-Serviço; Competências do Design, Estratégia do Design.

\begin{abstract}
In the last century, Design played an active role in developing and disseminating unsustainable life styles. This article revises the existing heuristics for sustainable development and its implication in the design activity, in order to identify new avenues where design may contribute to a sustainable society. This critical review of the state-of-the-art focuses on the new roles required by Design as a profession and its implications on Design Education. The bottleneck for disseminating these new roles in Brazil includes the lack of lecturers, the lack of didactic material and the lack of methodologies that enable design to work at a systems level, including the design of product-service systems.
\end{abstract}


Keywords: System Design for Sustainability; Product-Service Systems; Roles of Design; Design Strategy.

\section{Introdução}

As tendências mundiais direcionadas à redução dos impactos ambientais têm provocado novos posicionamentos do setor produtivo no que tange à preservação ambiental, conforme relatam Manzini e Vezolli (2002). De acordo com essas afirmações, Santos (2008) defende que o design pode desempenhar um papel fundamental, tornando exeqüível a proposição de novos cenários e sistemas (baseados nos requisitos da sustentabilidade) e assumindo novas funções diante dos problemas sócio-econômicos e ambientais.

Na década de 1970 do século passado, Papanek (1984) já identificava a responsabilidade social do designer e os problemas causados ao meio ambiente, decorrentes da produção em massa. Nesta nova perspectiva o design deixa de ser parte do problema (o design enquanto uma das disciplinas do conhecimento que dá suporte ao estilo de consumo atual) e passa a ser parte integrante da solução, no que se refere ao desafio da sustentabilidade. Atualmente, diversos autores defendem a idéia de que o design deve contribuir para a mudança do perfil atual da produção e do consumo, conduzindo à resolução de problemas reais e a mudanças efetivas no sentido de uma maior sustentabilidade desses sistemas (vide LEWIS et al, 2001; MANZINI; VEZZOLI, 2002; SHERWIN, 2004).

Neste contexto, o presente artigo aborda o estado da pesquisa e da prática do design para a sustentabilidade. As discussões abrangem as ferramentas e abordagens existentes para a inclusão dos requisitos sustentáveis no projeto, bem como discute suas implicações na educação, a qual é um dos pontos-chave para que o design torne-se um agente ativo na transição para estilos de vida mais sustentáveis.

\section{O design e a sustentabilidade}

Nas últimas duas décadas, desde que o conceito de desenvolvimento sustentável passou a fazer parte das políticas internacionais de modo mais efetivo, o meio ambiente passou de uma fonte inesgotável de recursos e 
receptor de resíduos para o status de ativo da sociedade global e tem sido o foco de contínuas discussões em nível mundial, conforme afirmam Borges e Tachibana (2005). Neste contexto, os tradicionais domínios do design (até então profundamente interconectados com os padrões de produção e consumo determinados pelo meio industrial) passam a sofrer influências e incluir as questões da sustentabilidade na pauta de discussões e ações nos níveis nacionais e internacionais.

Esses questionamentos são bastante recentes e, portanto, ainda se encontram em processo de desenvolvimento e aperfeiçoamento. Contudo Santos (2008) defende que somente uma abordagem ampla e integrada das competências do designer poderá viabilizar a passagem do projeto unicamente focado no produto para projetos sistêmicos, baseados em requisitos ambientais e sócio-éticos, além dos econômicos. Para tanto, torna-se urgente e necessário efetuar uma profunda reavaliação dos fundamentos e habilidades do design, de modo que atividade projetual torne-se mais promissora, acessível, eficaz e reprodutível, além de capacitar o designer para atuar de forma crítica e participativa e não como mero executor de projetos, submisso a interesses comerciais e mercadológicos.

O International Council of Societies of Industrial Design - ICSID (2008), já aborda o design sob uma ótica mais ampla e define como uma de suas principais missões "tomar conhecimento e avaliar as interconexões estruturais, organizacionais, funcionais, expressivas e econômicas com o objetivo de reforçar a sustentabilidade global e a proteção ambiental (ética global)". Para o ICSID (2008) o design também necessita propiciar benefícios e liberdade para toda a comunidade humana, individual e coletiva, incluindo usuários, produtores e protagonistas do mercado (ética social); apoiando a diversidade cultural apesar da globalização mundial (ética cultural); fornecendo produtos, serviços e sistemas, que são as formas expressivas (semiologia) e coerentes com (estética) sua própria complexidade.

De acordo com essa abordagem, Manzini (2008) considera que o design está atuando em uma sociedade na qual, segundo a sociologia contemporânea, "todos participam do projeto", portanto torna-se necessário considerar o design como parte de um complexo sistema de concepção. Corroborando com essa visão, Santos (2008) defende que o design é uma das profissões que por diversas vezes foi apontada como contribuinte para os principais problemas ambientais que nos defrontamos atualmente, porém possui grande potencial para desenvolver atribuições favoráveis ao processo 
de mudança. No entanto, mesmo quando se torna possível atuar além dos produtos e serviços a profissão se encontra restrita ao desempenho estratégico do próprio sistema, deste modo pode contribuir apenas com a educação dos produtores e consumidores sobre questões relacionadas com a sustentabilidade, no entanto se conseguir avançar em suas proposições pode partir para um efetivo papel de liderança (SANTOS, 2008).

De acordo com esses pressupostos, Tischner e Verkuijl (2006) afirmam que já se pode notar um crescente interesse na comunidade de designers, em buscar formas viáveis para contribuir de maneira inovadora para a sustentabilidade em situações reais, ao invés de empregar recursos no simples redesign de produtos para mercados saturados e com recursos econômicos abundantes. Como exemplo pode-se citar o projeto Rent-o-box desenvolvido pelo Econcept (Alemanha) essencialmente baseado nos conceitos de utilização e compartilhamento (ECONCEPT, 2009).

O projeto consiste em uma unidade móvel para trabalho remoto (de uso compartilhado) completa e auto-suficiente, que pode reduzir a distância entre o trabalhador e o local de trabalho, pois pode ser implantada em qualquer lugar. O escritório móvel oferece uma moderna infra-estrutura tecnológica para atender as necessidades de trabalhadores nômades, a qual pode ser comparada com a maioria dos escritórios modernos. O usuário pode reservar via Internet ou por telefone através de um operador de serviço e pagar por demanda ou por tempo de utilização. $O$ modelo utiliza painéis solares, captação de águas pluviais e células de combustível e demonstrou ser uma alternativa ambientalmente viável por meio da análise de ciclo de vida.

No entanto, propostas como essa, que buscam soluções para as questões socioambientais, ainda estão longe de ser um movimento de massas, pois embora o sistema produtivo já consiga vislumbrar novos direcionamentos focados em soluções sistêmicas, estes ainda possuem lacunas metodológicas e conceituais. Por outro lado, essas soluções também se apresentam como uma concepção relativamente nova no âmbito da pesquisa e da prática e se caracterizam pela tensão entre a globalização econômica e cultural e a emergência dos limites ambientais.

\section{Novas dimensões para o design}


Desde que o tema da sustentabilidade emergiu nos debates internacionais os tradicionais domínios do design tem se expandido para além das características estéticas e funcionais do produto. Segundo Morelli (2002) as competências do design se estendem para a observação e interferência nos fenômenos socioambientais e econômicos a fim de propor novos cenários plausíveis e baseados em elementos reais, tendo em vista uma maior contribuição para o meio ambiente e para a sociedade.

A ampliação das competências do design permite a ampliação do seu escopo de atuação (vide Figura 1) e exige a combinação de elementos heterogêneos como, por exemplo, as dimensões socioculturais, os aspectos organizacionais e a construção social da tecnologia (MORELLI, 2002).

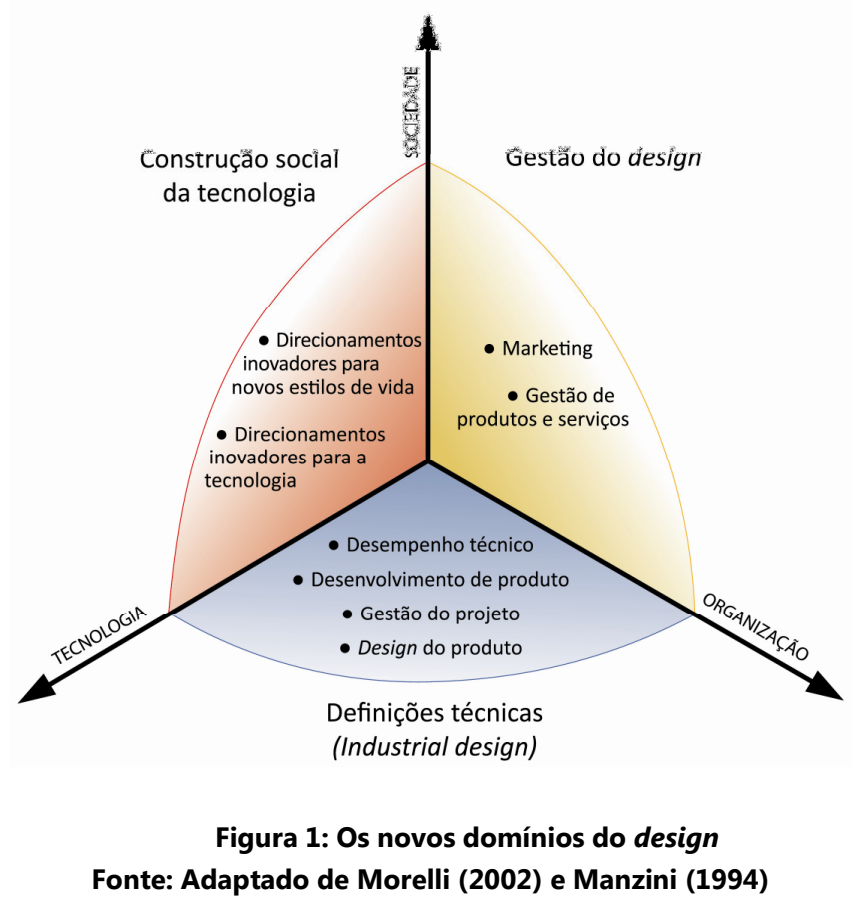

A partir dessas competências o design pode desempenhar um papel fundamental na construção de cenários inovadores direcionados para a sustentabilidade e, para tanto, Manzini (1994) sugere uma revisão dos conceitos fundamentais como a forma, a função, o cliente, o usuário e o mercado, incluindo considerações sobre o papel da tecnologia, da estética e do design em si. Neste sentido, a figura 1 representa a inclusão dos aspectos citados por Manzini (1994) e propostos por Morelli (2002) para que o designer possa adquirir um entendimento global da estrutura sociocultural, 
organizacional e tecnológica que envolve o projeto e, desta forma, contribuir para a construção de soluções ambientalmente viáveis e bem aceitas pelos atores envolvidos.

No entanto, Vezzoli (2007) observa que a transição para uma sociedade sustentável requer um longo e complexo processo coletivo de aprendizagem, no qual (além do designer) cada ator social terá de desempenhar um importante papel, adquirindo novas capacidades e assumindo novas responsabilidades de atuação. Porém, o autor defende a validade do papel da pesquisa em design em relação à produção de sistemas educativos, ferramentas e métodos direcionados para uma nova geração de educadores e designers, que lhes permita enfrentar de forma mais eficaz a transição para uma sociedade sustentável.

\section{O estado atual das novas dimensões do design}

Vezzoli (2007) apresenta o estado atual do desenvolvimento das novas dimensões do design para a sustentabilidade, de acordo com os níveis de consolidação e de disseminação. Sendo que os níveis de consolidação derivam dos resultados das pesquisas em design e os níveis de disseminação advêm das ações práticas e abrangem a educação e a pesquisa relativas aos temas representados na Figura 2.

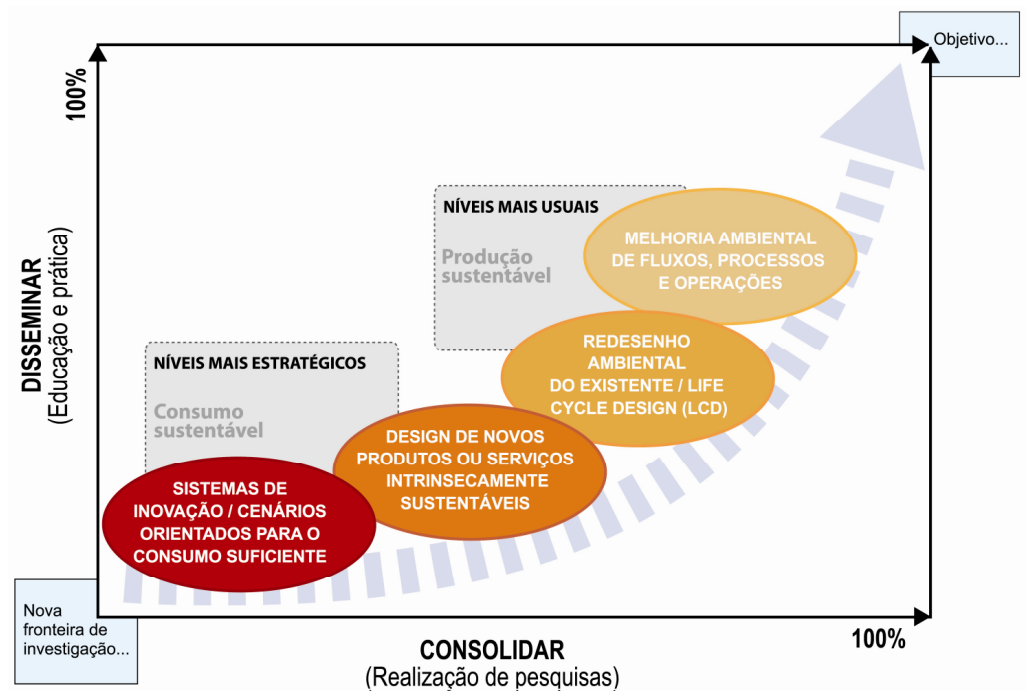

Figura 2: Níveis do design para a sustentabilidade (disseminação e consolidação) Fonte: Adaptado de Manzini e Vezzoli (2002) e Vezzoli (2007) 
Na Figura 2 foram relacionadas as categorias do design para a sustentabilidade citadas em Manzini e Vezzoli (2002, p. 20) e Vezzoli (2007, pag. 45-50) associadas aos níveis de disseminação e consolidação apresentados por Manzini e Vezzoli (2002, p. 41) e Vezzoli (2007, pag. 51).

Para a articulação entre as atividades projetuais do design e a preservação socioambiental em seus diversos desdobramentos, Manzini e Vezzoli (2002) fazem referência aos quatro níveis fundamentais de interferência no projeto (vide Figura 2) e concluem que a prática atual tem sido focada nas categorias mais usuais.

Segundo Vezzoli (2007) essas classificações não representam necessariamente uma evolução cronológica e também não definem precisamente as fronteiras entre uma e outra dimensão, no entanto podem ser úteis para o entendimento esquemático das contribuições do design para a sustentabilidade.

A seguir será apresentada a situação em que se encontram as ações relativas à prática da sustentabilidade no âmbito do design, nos níveis identificados anteriormente.

a) Melhoria ambiental de fluxos de processos e operações: segundo Epelbaum (2004) a gestão de produtos e processos (também denominadas de tecnologias de fim de linha ou end-of-pipe) e as certificações ambientais iniciaram sua implementação a partir das décadas de 1960 e 1970 do século passado, como solução imediata para atender os requisitos ambientais mais restritivos.

Segundo Epelbaum (2004) a partir da década de 1990, pesquisadores e instituições passam a defender a mudança dos padrões tecnológicos para tecnologias mais limpas, relacionando esse fator de mudança às vantagens técnicas às políticas públicas, às práticas corporativas e ao interesse econômico. Devido a esses fatores esta categoria também é a mais abordada pelas instituições de ensino superior em Design.

Desde então vários países centrais incluíram esse procedimento como norma em sua legislação, porém no caso de países de industrialização periférica ou tardia (como o Brasil) a disseminação ainda não é satisfatória, pois existe uma grande heterogeneidade estrutural entre os setores produtivos, o que acentua as diferenças nas padronizações tecnológicas, conforme afirma Young (1998). 
Por outro lado, Santos (2009) afirma que a redução do impacto ambiental neste nível sofre variações nos diferentes ramos de atividades, por exemplo, no setor têxtil, a SusHouse (2000) coloca a otimização do ciclo de vida e a redução dos recursos utilizados na fase de uso como uma melhoria mais importante do que a redução do consumo de recursos e da toxidade na fase de produção.

b) $O$ redesenho ambiental do existente: os procedimentos voltados à gestão ambiental de produtos tiveram início por volta da década de 1970, mas se encontravam restritos a estudos acadêmicos de um grupo de designers que promoviam idéias e conceitos avançados para a época, desta forma não atingiu de maneira abrangente os setores industriais.

Atualmente, no âmbito do design, essa categoria se divide em dois diferentes aspectos: o foco no produto, por meio do redesign ou do ecodesign e o foco na Análise do Ciclo de Vida (ACV). Essas interferências no projeto podem assumir diferentes níveis de atuação sobre os requisitos da sustentabilidade ambiental, podendo variar desde a redução de materiais, reutilização e biocompatibilidade até a minimização dos impactos ambientais decorrentes da avaliação de todas as fases do ciclo de vida do produto. Nesse contexto não ocorre uma alteração profunda no estilo de vida e de consumo dos usuários, mas o design pode influenciar as escolhas do consumidor, iniciando um direcionamento para a sustentabilidade.

Verifica-se que essa categoria já se encontra em um bom nível de consolidação, visto que já foram desenvolvidas diversas ferramentas e softwares para auxiliar o designer na análise da sustentabilidade na fase do projeto. Como exemplo pode-se citar a ferramenta D4S - Design for Sustainability, a qual foi desenvolvida pela UNEP (2004) em parceria com a Delft University of Technology e objetiva orientar o projeto de produtos com menor impacto ambiental.

Todavia ainda possui um discreto nível de disseminação no plano prático, pois as forças impulsionadoras para a disseminação desses procedimentos seriam as políticas públicas, os requisitos legais e a responsabilidade dos fabricantes pelo ciclo de vida do produto, entretanto no Brasil essas normatizações ainda necessitam de fortalecimento por parte dos órgãos governamentais (EPELBAUM, 2004). 
Além desses aspectos, outro fator crucial, no Brasil, é o ensino superior em Design, o qual ainda não promove a educação profissional voltada para as práticas da sustentabilidade, de forma satisfatória. Por outro lado, segundo dados do Instituto Akatu (2007), o perfil do consumidor brasileiro tem sofrido constantes alterações e os conceitos de solidariedade, sustentabilidade e coletividade tem apresentado progressivo fortalecimento em todas as camadas da população, embora ainda seja bastante reduzido quando comparado com índices de países desenvolvidos.

c) Design de novos produtos ou serviços intrinsecamente sustentáveis: esta dimensão do design trata de oferecer produtos ou serviços radicalmente coerentes com as perspectivas da sustentabilidade, além de socialmente aceitáveis e que promovam a modificação cultural e comportamental dos consumidores.

Para atingir esses objetivos Mont (2000) afirma que o desafio consiste em atravessar as fronteiras dos conceitos tradicionais a fim de atingir as metas do Fator 10, ou seja, aumentar em 10 vezes a eco-eficiência do processo produtivo, reduzindo a pressão sobre o meio ambiente. Nesses casos uma política ambiental integrada ao produto melhora a tomada de decisão por parte do consumidor e ao mesmo tempo incentiva o sistema produtivo para o desenvolvimento sustentável de bens e serviços.

Para atuar nesse nível do projeto faz-se necessário, segundo Manzini e Vezzoli (2002), capacitar o sistema produtivo para corresponder à expectativa social de bem-estar, atuando no nível comportamental dos consumidores. Para tanto, o designer deve envolver os usuários no processo, tornando-os "co-criadores" de soluções, pois o conhecimento relativo à prática diária é indispensável para o desenvolvimento de soluções adequadas e valioso para a aceitação das soluções propostas.

Neste caso o termo co-design pode ser considerado como a readequação de soluções presentes no cotidiano com forte ligação com a cultura local. Como exemplo, pode-se citar o filtro de água batizado de "São João", o qual é um produto tipicamente brasileiro criado pelo ceramista e empresário Victor Lamparelli no final da década de 1920, no interior do estado de São Paulo. Sua cerâmica vermelha mantinha a água filtrada sempre fresca, também possuía desenhos pintados à mão e tornou-se um símbolo de status, ocupando um lugar de destaque nas cozinhas da elite social da época. Até hoje se mantém como o mais lembrado e o mais 
vendido filtro de água do país e, sendo um objeto durável, poderia substituir a utilização de bombonas d'água em PVC ou plástico, tão comuns atualmente (CERÂMICA STÉFANI, 2009).

\section{d) Sistemas de inovação - cenários que promovam o consumo}

suficiente: outra expressão que tem sido bastante utilizada nas discussões científicas nos últimos anos, como uma interpretação mais precisa da sustentabilidade é o termo "Sistemas de inovação" ou "Design de sistemas eco-eficientes".

Esta nova dimensão do design diz respeito a mudanças profundas nos modelos de consumo e produção e no estilo de vida atual, pois se amplia além do escopo do produto, incidindo sobre todo o sistema de demanda, atendendo às necessidades e aos desejos do usuário, ao mesmo tempo em que promove o consumo "suficiente" (VEZZOLI, 2007). Alcott (2008) define a suficiência como a satisfação das necessidades pela classe que atualmente não possui poder de compra e a redução voluntária do consumo pelas classes de maior poder aquisitivo, objetivando a redução dos custos ambientais e o benefício para o presente e o futuro das espécies existentes no planeta.

Embora o debate sobre Sistemas de Inovação seja amplo e ainda se encontre em desenvolvimento, pesquisadores em design também o correlacionam ao termo "Sistemas Produto-Serviço (PSS)". Neste caso, o PSS se apresenta como o resultado de uma estratégia inovadora que se desloca da aquisição de produtos físicos para a utilização de um sistema de produtos e serviços capazes de satisfazer às demandas requeridas (VEZZOLI, 2007).

Outro recente aspecto abordado pela pesquisa em design tem sido as ferramentas e métodos do design para a eqüidade e coesão social. Nesta categoria o design tem buscado compreender as implicações da dimensão social da sustentabilidade em suas atividades projetuais. Neste nível são incluídos (entre outros aspectos) a equidade e justiça nas relações com os stakeholders; o consumo sustentável; a coesão social e a valorização dos recursos locais. No entanto, o design para a eqüidade e coesão social situase em fase inicial de elaboração no nível técnico, apresentando-se como uma nova fronteira do design e, conseqüentemente possui poucas propostas metodológicas direcionadas para a prática (VEZZOLI, 2007). 


\section{Conclusões e observações finais}

Verifica-se que o design tem ampliado seu escopo de atuação de acordo com os preceitos e necessidades do atual modelo de desenvolvimento, no entanto faz-se necessário promover e orientar as ações em âmbito local, para elevar o grau de consolidação e disseminação do design para a sustentabilidade. Neste contexto, também se observa que tanto a consolidação quanto a prática das novas dimensões do design ainda necessitam passar pela superação da tradicional inércia de todos os interessados na aceitação, na adoção e na utilização de novos produtos e/ou serviços baseados nos requisitos sustentáveis.

Como um dos principais entraves para a disseminação e consolidação do design para a sustentabilidade identifica-se a própria concepção do design (da forma como tem sido convencionalmente entendida ao longo da história), pois o mesmo tem a produção industrial como sua principal finalidade.

A introdução do design no Brasil também foi realizada como uma estratégia de apoio aos sistemas de produção, no entanto esse sistema (que possui seu modelo de desenvolvimento baseado fortemente no desenvolvimento tecnológico e na escala de produção) passa atualmente por um profundo questionamento de suas características inerentes. Desta forma o design também questiona seus princípios e premissas, pois estão fundamentadas no modelo que se encontra em crise.

Na educação superior em Design também se observa a mesma situação, pois a maioria dos cursos também apóia o desenvolvimento de produtos voltados ao atual sistema de produção e consumo, no entanto com a emergência das questões da sustentabilidade há uma lacuna de profissionais para preencher as especialidades requeridas. Nesta área, mesmo com os estudos já desenvolvidos, ainda não existem recursos humanos suficientes e respaldo teórico para o desenvolvimento de metodologias e material didático para o ensino do design para a sustentabilidade.

Por outro lado, no Brasil, a indústria e o mercado consumidor ainda não valorizam de forma significativa, o consumerismo ético, o qual se caracteriza pela produção e pelo consumo racional, controlado e responsável e que considera as conseqüências econômicas, sociais, culturais e ambientais do próprio ato de consumir. Desta forma, quando se produz para um mercado que possui demandas cada vez mais urgentes e instantâneas, o designer (que 
atua de acordo com os padrões convencionais) se encontra inabilitado para desenvolver atividades projetuais que incluam os requisitos ambientais, sociais ou culturais da sustentabilidade. Visto que os procedimentos para a execução desse tipo de projeto demandam um tempo maior, além do desenvolvimento de novas competências e do envolvimento com toda a cadeia de atores envolvidos no processo.

Com o objetivo de ampliar as dimensões do design e a atuação do designer para além do foco do produto, as proposições apresentadas necessitam de desenvolvimento contínuo, pois se apresentam como uma nova categoria de projeto, a qual integra questões econômicas, ambientais, culturais e sócio-éticas, abrangendo um pensamento global e sistêmico que permeia a concepção do projeto como um todo.

\section{Referências}

ALCOTT, Blake. The sufficiency strategy: Would rich-world frugality lower environmental impact? Ecological Economics. 64 (2008) 770 - 786.

BORGES, F. H.; TACHIBANA, W. K. A evolução da preocupação ambiental e seus reflexos no ambiente dos negócios: uma abordagem histórica. In: Encontro Nacional de Engenharia de Produção. Anais do XXV ENEGEP... Porto Alegre, 2005. Disponível em http://www.abepro.org.br/ biblioteca/ENEGEP2005_Enegep1005_1433.pdf Acesso em: 10 fev. 2009.

CERAMICA STÉFANI. Disponível em http://www.ceramicastefani.com.br /index.php Acesso em: 10 mai. 2009.

ECONCEPT. The Sustainable Office. Disponível em http://www.econcept. org/index.php?option $=$ com_content\&task $=$ view\&id $=65 \& I t e m i d=44$ Acesso em: 10 fev. 2009.

EPELBAUM, M. A influência da gestão ambiental na competitividade e no sucesso empresarial. 190f. Dissertação (Mestrado) - Departamento de Engenharia de Produção, Escola Politécnica da Universidade de São Paulo, São Paulo, 2004. 
ICSID - International Council of Societies of Industrial Design. Disponível em www.icsid.org/about/about/ articles31.htm Acesso em: 30 set. 2008.

INSTITUTO AKATU. Pesquisa 2006 e 2007 (RSE). Percepção do Consumidor Brasileiro. 2007. Disponível em http://www.akatu.org.br/akatu_acao/ publicacoes/perfil-do-consumidor Acesso em: 10 fev. 2009.

LEWIS, H. et al. Design + environment: A global guide to designing greener goods. London: Greenleaf, 2001.

MANZINI, E. Design, environment and social quality: from "existenzminimum" to "quality maximum". Design Issues, v. 10, n. 1, p. 37-43. Spring, 1994.

Designing networks and metadesign. Some introductory notes. Disponível em: http://www.sustainable-everyday.net/manzini/ Acesso em: 25 dez. 2008.

MANZINI, E.; VEZZOLI, C. $\mathbf{O}$ desenvolvimento de produtos sustentáveis os requisitos ambientais dos produtos industriais. São Paulo: Edusp, 2002.

MONT, O. Product Service-Systems. Final report. IIIEE, Lund University. Swedeen. 2000.

MORELLI, N. Designing Product/Service Systems: a Methodological Exploration. Design Issues: Vol.18, Number 3 (Summer 2002), pp. 3-17. 2002.

PAPANEK, V. Design for the real world. Second Edition. New York: Van Nostrand Reinhold, 1984.

SANTOS, A. Equity through Design: a Critical Literature Review. (No prelo). 2009.

SANTOS, A. Design Sustentável: Dimensão Ambiental. (no prelo). 2009.

SHERWIN, C. Design and sustainability: a discussion paper based on personal experience and observations. The Journal of Sustainable Product Design 4:21- 
31. Kluwer Academic Publishers. Holanda, 2004.

SUSHOUSE. The Clothing Care Function. Final Report, Sushouse Project. Published by the Faculty of Techology, Policy and Management, TBM, Delft University of Technology, The Netherlands. 2000.

TISCHNER, U.; VERKUIJL, M. Design for (Social) Sustainability and Radical Change. Score! Perspectives on Radical Changes to Sustainable Consumption and Production: p. 123-139. TNO Built Environment and Geosciences, Delft, the Netherlands: 2006.

UNEP - United Nations Environment Programme. D4S Methodology. Delft University, Delft: 2004. Disponível em http://www.d4s-de.org Acesso em: 30 set. 2008.

VEZZOLI, C. System design for sustainability. Theory, methods and tools for a sustainable "satisfaction-system" design. Maggioli Edtore. Milano, Italy, 2007.

YOUNG, C.E.F. Industrial pollution and export-oriented policies in Brazil. Revista Brasileira de Economia. 52(4): 543-562. 1998. 